\title{
Measurement of Yearly Wastage in Elementary Education
}

\author{
MANOJ KUMAR GUPTA, JAGDISH PRASAD and P. C. GUPTA \\ Department of Statistics, University of Rajasthan, Jaipur \\ Email: guptamanoj97@rediffmail.com,Jagdish55_singh@yahoo.co.in, \\ pcgupta44@yahoo.co.in
}

\begin{abstract}
The problem of wastage in Elementary Education System is becoming gradually very serious, across the world. Various methods have been proposed by researchers to measure real wastage in an Indian educational system, which seem to be inadequate because of multiple reasons. One of the main reasons is the occurrence of different type of wastages in elementary education system. Further, there no reliable and consistent database, of educational statistics, that are available. In this paper, we wish to propose a method for measuring the real wastage by using appropriate statistical technique of sampling.
\end{abstract}

Keywords: Universal enrollment, Universal retention, Never enrolled, Ever enrolled, Repetition, Internal wastage, External wastage, Cluster Sampling

\section{A. INTRODUCTION}

The goal of universal elementary education can be achieved by two major components namely universal enrollment and universal retention. For this purpose, the children of the age group 6-14 years can be classified into two classes, viz those who are presently out-of-schools and those who are presently enrolled in schools. First component of goal of universal elementary education (universal enrollment) is directly related to out-of-school children and the second component of goal of universal elementary education (universal retention) is directly related to in-school children. Hence, the aim of Sarva Shiksha Abhiyan (SSA) is to approach out-of-school children and enroll them in schools as well as to retain the enrolled children in the schools.

In case of elementary education, wastage can be classified in two parts - internal wastage and external wastage. Internal wastage means wastage of economic resources, used to achieve the universal retention and external wastage means wastage of human resources which could not be used to achieve universal enrollment. These wastages can be defined as:

1. Internal Wastage: This wastage occurs when enrolled children leave the school after spending some time or complete the course successfully after
Mathematical Journal of Interdisciplinary Sciences Vol. 2, No. 1, September 2013 pp. $25-41$

ChITKARA

C 2013 by Chitkara University. All Rights Reserved. 
Gupta, M.K.

Prasad, J.

Gupta, P.C. spending some more years than the prescribed duration. This wastage reflects our efforts to retain the enrolled children of the age group 6-14 years in school, complete their eight year elementary education and ensure them of quality education so that they are able to promote to the next level of education. The major components of this type of wastage are retention, repetition and promotion.

a. Retention: The term 'retention' means children who leave school during any part of the academic year without completing the course in which he/she is studying. This is the pre-mature withdrawal of children from school at any stage before the completion of course for any reason, except death and transferring to another school. This type of wastage occurs in external wastage also. Hence, this is the two-way wastagewastage of economic resources as well as wastage of human resources.

b. Repetition: This is defined as the retention of a child in a class for more than one year on account of unsatisfactory progress. Thus, if a student passes a class in two or more years, he/she constitutes a case of stagnation or repetition. This wastage is more serious than repetition because it prevents the next intake also. However, this type of wastage is reduced to a great extent after effective implementation of Right to Education Act, 2010.

c. Promotion: This is the wastage in which children complete the elementary education successfully but not transected to the upper level education. Hence, this wastage occurs when children leave their studies after taking primary/elementary education.

Planners of education have always expressed concern about educational wastage caused by repetition and retention. Due to such type of wastage, the country is not fulfilling the social demands for formal education. For effective management of an educational system, it is required that the retention rate should be improved by reducing educational wastage while maintaining the quality of the system at reasonable input costs.

2. External Wastage: This wastage occurs due to children who are out of school and are never enrolled in any school as well as children enrolled in the school but due to some socio economic reasons had left their studies before completion of elementary education. This wastage reflects our efforts to enroll the children in the schools and complete the eight year elementary education. The major components of this type of wastage are never enrollment and dropout. 
a. Never Enrollment: Never enrollment means school is available for the child to take admission but the child could not reach to the school due to some socio-economic and educational factors. In elementary education system, external wastage due to never enrollment is very serious and must be controlled.

b. Dropout: Dropout means children were enrolled in the school but could not complete the elementary education due to some socioeconomic reasons and left their studies.

By measuring the wastage, efficiency of elementary education can be obtained because efficiency is inversely proportional to wastage. Basically, measurement of efficiency in elementary education is based on internal and external wastage.

\section{B. MEASUREMENT OF INTERNAL WASTAGE}

Some attempts have been made by researchers namely Rao G.N. (1966), Tikkiwal B.D. (1966), Kamat A.R. (1968), Hajela D. (1969) and Tikkiwal G.C. (1978) to evolve formulae for measuring wastage but due to various reasons, these can not be applied in all the situations. Some of the reasons are

1. Within school system wastage, due to dropout which could have been occurred due to various reasons that are not registered in school records. Further, there is no reliable and comprehensive child tracking system available in our country.

2. There is no serious effort being made to collect the information about the children who are never enrolled.

In spite of these problems, certain methods have been in use for measuring internal wastage at any given level. Cohort method is extensively used for this purpose in which each and every child of the same cohort of the students is being tracked during the course.

Cohort Method: This is the ideal method to obtain a precise measurement of internal wastage in elementary education. By this method, we can measure only the internal wastage whereas external wastage can not be measure by this method. This method involves either longitudinal study in monitoring the process of a selected cohort of students through the educational cycle or through the retrospective study of school records in order to retrace the flow of students through the classes in past years. In the cohort method, individual student of class I cohort of a given year is tracked through the school records till all students of cohort are exhausted, or they complete the elementary education cycle or leave the system. This method is based on the fundamental concept
Measurement of Yearly Wastage in Elementary

Education 
Gupta, M.K.

Prasad, J.

Gupta, P.C. that for students enrolled in a given course at a certain year, there could be only three eventualities: (i) some of them will be promoted to the next higher class in the next school year (ii) other will dropout of school in the course of the year (iii) remaining will repeat the same class the next school year.

The formulae used in India for computing the indicator of wastage at school level is as follows:

Index of wastage $=1-($ Total optimum years/Total actual used years)

Where, 'optimum years' stands for the number of years required to 28 complete the prescribed course on the assumption that every student will make normal and regular progress from year to year. The 'actual used years' are, however calculated by continuing the total number of years spent in school by every student in the age-cohort (NCERT, 1968).

The procedure described above, however cannot be applied for quantifying the wastage at international level. When comparing educational wastage across nations, a great deal of caution needs to be exercised because educational systems are not alike structurally; and promotion policies and achievement norms differ to a great extent.

Estimators for Internal wastage due to retention \& repetition and nontransaction in next level education are suggested by Rao \& Tikkiwal (1966).

\section{The original estimator}

The Rao-Tikkiwal (1966) indicator estimates the total wastage of efficiency at two stages: the wastage of first stage, which takes into account the proportion of students who complete the course and the time spent in the course; and the second stage, which measures the validity of the learning and skills acquired during the course through the students' ability to successfully enter the next level of training or the labour market.

The Rao-Tikkiwal defined the measure of the internal wastage as follows:

Cohort means total students enrolled in a given course

Notation for measures of wastage in education in Indian educational system-

For a given course of education, let:

$\mathrm{d}=$ duration of the course;

$\mathrm{k}(\geq \mathrm{d})=$ the period of observation for each student of cohort admitted to the course;

$\mathrm{W}_{\mathrm{t}}=$ measure of total wastage;

$\mathrm{W}_{\mathrm{fs}}=$ measure of the wastage at the first stage;

$\mathrm{W}_{\mathrm{ss}}=$ measure of the wastage at the second stage; 
$\mathrm{W}_{\mathrm{d}}=$ measure of wastage due to dropout;

$\mathrm{W}_{\mathrm{s}}=$ measure of wastage due to repetition;

$\mathrm{N}=$ number of students in the cohort;

$\mathrm{N}_{1}$ = number of students of the cohort who complete the course in exactly ' $\mathrm{d}$ ' years;

$\mathrm{N}_{2 \mathrm{i}}=$ number of students who complete the course in ' $(\mathrm{d}+\mathrm{i})$ ' years, where $\mathrm{i}=1,2, \ldots \ldots \ldots, \mathrm{k}-\mathrm{d}$;

$\mathrm{N}_{2}=\sum_{i=1}^{k-d} \mathrm{~N}_{2 \mathrm{i}}=$ total number of students who complete the course in $(\mathrm{d}+\mathrm{i})$ years for all $i \geq 1$;

$\mathrm{N}_{3 \mathrm{i}}=$ number of students who dropout of the course after spending ' $\mathrm{i}$ ' years in it and leave the study, where $\mathrm{i}=1,2, \ldots \ldots \ldots, \mathrm{k}$;

$\mathrm{N}_{3}=\sum_{i=1}^{k} \mathrm{~N}_{3 \mathrm{i}}=$ total number of students who dropout of the course without completing it;

$\mathrm{M}=$ number of students, out of $\left(\mathrm{N}_{1}+\mathrm{N}_{2}\right)$, who are unable to join the profession requiring the course or to further study;

$\mathrm{N}=\mathrm{N}_{1}+\mathrm{N}_{2}+\mathrm{N}_{3}$

$\mathrm{U}_{1}=\sum_{i=1}^{k} \mathrm{iN}_{3 \mathrm{i}}=$ total number of years spent by the students, out if ' $\mathrm{N}$ ', who dropout the course up to the period ' $\mathrm{k}$ ';

$\mathrm{U}_{2}=\Sigma_{i=1}^{k-d}\left(\mathrm{i}_{2 \mathrm{i}}\right)=$ total number of additional years spent in the course by delayed successful students;

$\mathrm{U}_{3}=\mathrm{M} \times \mathrm{d}$

$\mathrm{U}=\mathrm{d}\left(\mathrm{N}_{1}+\mathrm{N}_{2}\right)+\sum_{i=1}^{k}\left(\mathrm{~N}_{2 \mathrm{i}}+\mathrm{i} \mathrm{N}_{3 \mathrm{i}}\right)=$ the total number of years spent in the course by the $\mathrm{N}$ students of the cohort, where each of $\mathrm{N}$ member is observed for a period $\mathrm{k}(\geq \mathrm{d})$ and where $\mathrm{N}_{2 \mathrm{i}}=0$ for $\mathrm{k}-\mathrm{d}<\mathrm{i} \leq \mathrm{k}$;

Further, let the population of $\mathrm{N}$ members be classified into the following $(2 \mathrm{k}-\mathrm{d}+1)$ mutually exclusive classes;

$\mathrm{N}_{1}=\mathrm{C}_{1}=$ the class of those students who complete the course in exactly d years;

$\mathrm{N}_{2}=\mathrm{C}_{2 \mathrm{i}}=$ the class of those students who complete the course in ( $\left.\mathrm{d}+\mathrm{i}\right)$ years where $\mathrm{i}=1,2, \ldots \ldots \ldots ., \mathrm{k}$-d;

$\mathrm{C}_{3 \mathrm{i}}=$ the class of those students who dropout of the course after spending ' $\mathrm{i}$ ' years in the course and sit idle, where $\mathrm{i}=1,2, \ldots \ldots ., \mathrm{k}$;

$\mathrm{N}_{3}=\mathrm{C}_{3 \mathrm{i}}$;

Now, $\quad \mathrm{W}_{\mathrm{d}}=\mathrm{U}_{1} / \mathrm{U} ; \quad \mathrm{Ws}=\mathrm{U}_{2} / \mathrm{U}$;

$$
\mathrm{W}_{\mathrm{fs}}=\mathrm{W}_{\mathrm{d}}+\mathrm{W}_{\mathrm{s}} ; \quad \mathrm{W}_{\mathrm{ss}}=\mathrm{U}_{3} / \mathrm{U} \text { and } \mathrm{W}_{\mathrm{t}}=\mathrm{W}_{\mathrm{fs}}+\mathrm{W}_{\mathrm{ss}}
$$


Gupta, M.K.

Prasad, J.

Gupta, P.C.

Here, measurement of wastage due to dropout includes all the students who dropout the school due to any reason but dropout due to death of a student and migration to another school is not a dropout in real sense. So, it has to identify students who dropout due to death and migration to another school and exclude them from total dropout students. For this, some modifications are required in Rao-Tikkiwal's estimator.

\section{Modified estimator for internal wastage}

For a given course of education, let:

$\mathrm{d}=$ duration of the course;

$\mathrm{k}(\geq \mathrm{d})=$ the period of observation for each student of cohort admitted to the course;

$\mathrm{W}_{\mathrm{i}}=$ measure of internal wastage;

$\mathrm{W}_{\mathrm{fs}}=$ measure of the wastage at the first stage;

$\mathrm{W}_{\mathrm{ss}}=$ measure of the wastage at the second stage;

$\mathrm{W}_{\mathrm{d}}=$ measure of wastage due to dropout;

$\mathrm{W}_{\mathrm{s}}=$ measure of wastage due to repetition;

$\mathrm{N}=$ number of students in the cohort;

$\mathrm{N}_{1}$ = number of students of the cohort who complete the course in exactly $\mathrm{d}$ years;

$\mathrm{N}_{2 \mathrm{i}}$ = number of students who complete the course in ` $(\mathrm{d}+\mathrm{i})^{\prime}$ ' years, where $\mathrm{i}=1$, $2, \ldots \ldots \ldots, \mathrm{k}-\mathrm{d}$

$\mathrm{N}_{2}=\sum_{i=1}^{k-d} \mathrm{~N}_{2 \mathrm{i}}=$ total number of students who complete the course in ` $(\mathrm{d}+\mathrm{i})^{\prime}$ years for all $\mathrm{i} \geq 1$;

$\mathrm{N}_{3 \mathrm{i}}=$ number of students who dropout of the course after spending 'i' years in it and leave the study, where $\mathrm{i}=1,2, \ldots \ldots \ldots, \mathrm{k}$;

$\mathrm{N}_{3 \mathrm{j}}=$ number of students who dropout of the course after spending ' $\mathrm{j}$ ' years in it and go for further study, where $\mathrm{j}=1,2, \ldots \ldots \ldots, \mathrm{k}$;

$\mathrm{N}_{3} \sum_{i=1, j=1}^{k}\left(\mathrm{~N}_{3 \mathrm{i}}+\mathrm{N}_{3 \mathrm{j}}\right)=$ total number of students who dropout of the course without complete it;

$\mathrm{M}=$ number of students, out of $\left(\mathrm{N}_{1}+\mathrm{N}_{2}\right)$, who are unable to join the profession requiring the course or who go for further study; 
$\mathrm{N}=\mathrm{N}_{1}+\mathrm{N}_{2}+\mathrm{N}_{3}$

$\mathrm{U}_{1}=\sum_{i=1, j=1}^{k}\left(\mathrm{i} \mathrm{N}_{3 \mathrm{i}}+\mathrm{j} \mathrm{N}_{3 \mathrm{j}}\right)=$ total number of years spent by the students, out if $\mathrm{N}$, who dropout the course up to the period $\mathrm{k}$;

$\mathrm{U}_{2}=\sum_{i=1}^{k-d}\left(\mathrm{i} \mathrm{N}_{2 \mathrm{i}}\right)=$ total number of additional years spent in the course by delayed successful students;

$\mathrm{U}_{3}=\mathrm{M} \times \mathrm{d}$;

$\mathrm{U}=\mathrm{d}\left(\mathrm{N}_{1}+\mathrm{N}_{2}\right)+\sum_{i=1, j=1}^{k}\left(\left(\mathrm{~N}_{2 \mathrm{i}}+\mathrm{iN}_{3 \mathrm{i}}\right)+\mathrm{jN}_{3 \mathrm{j}}\right)=$ the total number of years spent in the course by the $\mathrm{N}$ students of the cohort, where each of $\mathrm{N}$ member is observed for a period $\mathrm{k}\left(\geq \mathrm{d}\right.$ ) and where $\mathrm{N}_{2 \mathrm{i}}=0$ for $\mathrm{k}-\mathrm{d}<\mathrm{i} \leq \mathrm{k}$;

Further, let the population of $\mathrm{N}$ students be classified into the following $(2 \mathrm{k}-\mathrm{d}+1)$ mutually exclusive classes;

$\mathrm{N}_{1}=\mathrm{C}_{1}=$ the class of those students who complete the course in exactly ' $\mathrm{d}$ ' years;

$\mathrm{N}_{2}=\mathrm{C}_{2 \mathrm{i}}=$ the class of those students who complete the course in ' $(\mathrm{d}+\mathrm{i})^{\prime}$ 'years where $\mathrm{i}=1,2, \ldots \ldots \ldots, \mathrm{k}-\mathrm{d}$;

$\mathrm{C}_{3 \mathrm{i}}=$ the class of those students who dropout of the course after spending ' $\mathrm{i}$ ' years in the course and left the study, where $\mathrm{i}=1,2, \ldots \ldots \ldots, \mathrm{k}$;

$\mathrm{C}_{3 \mathrm{j}}=$ the class of those students who dropout of the course after spending ' $\mathrm{j}$ ' years in the course and go for further study, where $\mathrm{j}=1,2, \ldots \ldots \ldots, \mathrm{k}$;

$\mathrm{N}_{3}=\mathrm{C}_{3 \mathrm{i}}+\mathrm{C}_{3 \mathrm{j}}$;

Now, $\quad \mathrm{W}_{\mathrm{d}} *=\left\{\mathrm{U}_{1}-\sum_{j=1}^{k} \mathrm{j} \mathrm{N}_{3}\right\} / \mathrm{U} ; \quad \mathrm{W}_{\mathrm{s}}=\mathrm{U}_{2} / \mathrm{U}$;

$$
\mathrm{W}_{\mathrm{fs}}=\mathrm{W}_{\mathrm{d}}+\mathrm{W}_{\mathrm{s}} ; \quad \mathrm{W}_{\mathrm{ss}}=\mathrm{U}_{3} / \mathrm{U} \text { and } \mathrm{W}_{\mathrm{i}}=\mathrm{W}_{\mathrm{fs}}+\mathrm{W}_{\mathrm{ss}}
$$

*This is the actual wastage due to dropout children.

Limitations of Cohort Method: No doubt this is the best method to measure the internal wastage but is has some limitations to collect the information about the cohort students.

1. In this method, information is collected on the basis of school records. In our elementary education system, it is in practice that the child migrates to another school without informing the school or without getting the transfer certificate as well as information about death of a child is not registered in school records. Hence, the school records does not show the actual reasons of dropout and the students who dropped out of school due to migration and death are counted in measurement of wastage.
Measurement of Yearly Wastage in Elementary

Education 
Gupta, M.K.

Prasad, J.

Gupta, P.C.
2. By this method we are unable to estimate the wastage due to never enrolled children because these types of children are not tracked in the cohort study.

\section{Child Tracking System}

The general objective of the Child Tracking System (CTS) is to track each and every child in the relevant age group throughout the country through census survey of households and educational institutions of all children in the age group 0-14 years with details of each and every child such as an unique child code, his/her name, date of birth, sex, social group, educational status reasons for out-of-school and data on other related key variables by a particular reference period every year.

By this system, we can measure the internal wastage as well external wastage. Most countries have their Educational Management Information System (EMIS). India also has an EMIS which is termed as District Information of School Education (DISE). DISE data is totally school-based which means that DISE data is entered by schools on the basis of school records. Hence, EMIS captures only the information of in-school children and suffers from the major limitation of capturing some of the important information of never enrolled and dropout children in elementary education system. Besides, given the time-lag in population census enumerations, planning and monitoring exercised in elementary education resort to projection of child population in the relevant age group. There is, therefore, a need to develop comprehensive database of both in-school and out-of-school children in the relevant age groups through a CTS.

CTS for out-of-school children is not being done in most of the states of India. So, the question arises that what is the way by which external wastage can be measured. To measure the external wastage, a sample survey may be conducted and external wastage in elementary education can be measured. On the basis of sample estimates, the wastage of whole elementary education system can be estimated.

\section{MEASUREMENT OF EXTERNAL WASTAGE}

Notation for measures of external wastage in elementary educationFor a given year, let:

$\mathrm{W}_{\mathrm{e}}=$ measure of external wastage

$\mathrm{W}_{\mathrm{ne}}=$ measure of wastage due to never enrolled children

$\mathrm{W}_{\mathrm{ee}}=$ measure of wastage due to dropout children

$\mathrm{N}=$ total number of children of the age group 6-14 years 
$\mathrm{N}_{\mathrm{e}}$ = number of school children of the age group 6-14 years who are presently enrolled

$\mathrm{N}_{\mathrm{ne}}=$ number of out of school children of the age group 6-14 years who never enrolled

$\mathrm{N}_{\mathrm{ee}}$ = number of out of school children of the age group 6-14 years who dropped out

$$
\begin{gathered}
\mathrm{N}=\mathrm{N}_{\mathrm{e}}+\mathrm{N}_{\mathrm{ne}}+\mathrm{N}_{\mathrm{ee}} \\
\mathrm{W}_{\mathrm{ne}}=\mathrm{N}_{\mathrm{ne}} / \mathrm{N} ; \quad \mathrm{W}_{\mathrm{ee}}=\mathrm{N}_{\mathrm{ee}} / \mathrm{N} \text { and } \mathrm{W}_{\mathrm{e}}=\mathrm{W}_{\mathrm{ne}}+\mathrm{W}_{\mathrm{ee}}
\end{gathered}
$$

\section{A sampling method to evaluate $\mathrm{W}_{\mathrm{ne}}, \mathrm{W}_{\mathrm{ee}}$ and $\mathrm{W}_{\mathrm{e}}$ of a sampling year}

Let the population of children of the age group 6-14 yrs be subdivided into $\mathrm{N}$ clusters. The $i^{\text {th }}$ cluster consist of $\mathrm{M}_{\mathrm{i}}$ number of children where $\mathrm{i}=1,2,-----, \mathrm{N}$.

Clustering of geographical area can be made on the basis of population under study. Number of clusters (N) should be as more as possible subjected to condition that the clusters should be so formed that the variation between the cluster means is as small as possible, while the variation within clusters is as much as possible.

Further, let a sample of ' $\mathrm{n}$ ' clusters be selected from ' $\mathrm{N}$ ' clusters by using simple random sampling without replacement (SRSWOR). Size of the sample (n) depends on that sample that properly represents the population.

Further, let:

$\overline{\mathrm{M}}=\frac{1}{\mathrm{n}} \sum_{\mathrm{i}=1}^{\mathrm{n}} \mathrm{M}_{\mathrm{i}}$; average size of clusters in the sample

$p_{i}=\frac{1}{M_{i}} \sum_{j=1}^{M_{i}} a_{i j} ;$ proportion of the children having characteristic $A$ in the $\mathrm{i}^{\text {th }}$ cluster

where, $\mathrm{a}_{\mathrm{ij}}=1$, if child having characteristic A, otherwise $0, \mathrm{i}=1,2, \ldots \ldots, \mathrm{n}$ and $\mathrm{j}=1,2, \ldots \ldots, \mathrm{M}_{\mathrm{i}}$

$\mathrm{p}=\frac{1}{\mathrm{n}}\left(\sum_{\mathrm{i}=1}^{\mathrm{n}} \mathrm{p}_{\mathrm{i}}\right)$; proportion of children having characteristic $\mathrm{A}$ in the sample

Further, Let:

$$
\begin{gathered}
U_{i j}=\frac{M_{i}}{\bar{M}} a_{i j} \\
\bar{u}_{1 .}=\frac{1}{M_{i}} \sum_{j=1}^{M_{i}} u_{i j}=\frac{M_{i}}{\bar{M}} p_{i}
\end{gathered}
$$


Gupta, M.K.

Prasad, J.

Gupta, P.C.

$$
\mathrm{V}_{\mathrm{i}}=\frac{\mathrm{M}_{\mathrm{i}}}{\overline{\mathrm{M}}}
$$

$$
\mathrm{p}=\frac{\sum_{\mathrm{i}=1}^{\mathrm{n}} \mathrm{M}_{\mathrm{i}} \mathrm{p}_{\mathrm{i}}}{\sum_{\mathrm{i}=1}^{\mathrm{n}} \mathrm{M}_{\mathrm{i}}}=\frac{1}{\mathrm{n}} \sum_{\mathrm{i}=1}^{\mathrm{n}} \frac{\mathrm{M}_{\mathrm{i}}}{\overline{\mathrm{M}}} \mathrm{p}_{\mathrm{i}}=\frac{1}{\mathrm{n}} \sum_{\mathrm{i}=1}^{\mathrm{n}} \overline{\mathrm{u}}_{1 .}=\overline{\mathrm{u}}_{.}
$$

$$
\begin{gathered}
\overline{\mathrm{V}}=\frac{1}{\mathrm{n}} \sum_{\mathrm{i}=1}^{\mathrm{n}} \mathrm{V}_{\mathrm{i}} \\
\mathrm{S}_{\mathrm{uv}}^{2}=\frac{1}{\mathrm{n}-1} \sum_{\mathrm{i}=1}^{\mathrm{n}} \frac{\mathrm{M}_{\mathrm{i}}^{2}}{\overline{\mathrm{M}}^{2}}\left(\mathrm{p}_{\mathrm{i}}-\mathrm{p}\right)^{2} \\
\mathrm{~S}_{\mathrm{u}}^{2}=\frac{1}{\mathrm{n}-1} \sum_{\mathrm{i}=1}^{\mathrm{n}}\left(\frac{\mathrm{M}_{\mathrm{i}}}{\overline{\mathrm{M}}} \mathrm{p}_{\mathrm{i}}-\mathrm{p}\right)^{2} \\
\mathrm{~S}_{\mathrm{v}}^{2}=\frac{1}{\mathrm{n}-1} \sum_{\mathrm{i}=1}^{\mathrm{n}}\left(\mathrm{v}_{\mathrm{i}}-\overline{\mathrm{v}}\right)^{2}
\end{gathered}
$$

Case I : Relationship between 'u' and 'v' is linear and does not pass through the origin

The regression estimator of wastage will be

$$
\left(\mathrm{P}_{\mathrm{W}}\right)_{\mathrm{reg}}=\mathrm{p}+\widehat{\beta_{\mathrm{uv}}}(1-\overline{\mathrm{v}}) ; \text { where, } \widehat{\beta_{\mathrm{uv}}}=\frac{\mathrm{s}_{\mathrm{uv}}}{\mathrm{s}_{\mathrm{v}}^{2}}
$$

The estimate of bias of the regression estimator:

$\widehat{\operatorname{Blas}}\left(\mathrm{P}_{\mathrm{W}}\right)_{\text {reg }} \simeq \widehat{\beta_{\mathrm{uv}}}(1-\overline{\mathrm{v}})$ which will be negligible if ' $\mathrm{n}$ ' is large

The estimate of Mean square error of regression estimator:

$$
\widehat{\operatorname{MSE}}\left(\mathrm{P}_{\mathrm{w}}\right)_{\mathrm{reg}} \simeq\left(\frac{1}{\mathrm{n}}-\frac{1}{\mathrm{~N}}\right) \mathrm{S}_{\mathrm{u}}^{2}\left(1-\rho_{\mathrm{uv}}^{2}\right)
$$

where $\rho_{u v}$ is correlation coefficient between $\mathrm{M}_{\mathrm{i}}$ and $\mathrm{p}_{\mathrm{i}}$

Case II : Relationship between $\mathrm{u}$ and $\mathrm{v}$ is linear and passing through the origin

The ratio estimator of wastage will be the best linear unbiased estimator in the class and is given by: 


$$
\left(\mathrm{P}_{\mathrm{W}}\right)_{\mathrm{r}}=\frac{\mathrm{p}}{\overline{\mathrm{V}}}
$$

If the relationship between ' $u$ ' and ' $v$ ' is linear but does not pass through the origin, then the ratio will be biased estimate of it and the bias is given by:

$$
\widehat{\operatorname{Bias}}\left(\mathrm{P}_{\mathrm{w}}\right)_{r} \simeq \frac{1}{n}\left(p S_{v}^{2}-S_{u v}^{2}\right)
$$

The estimate of Mean square error of ratio estimator is:

$$
\widehat{\operatorname{MSE}}\left(\mathrm{P}_{\mathrm{W}}\right)_{r} \simeq\left(\frac{1}{n}-\frac{1}{\mathrm{~N}}\right) \mathrm{S}_{\mathrm{uv}}^{2}
$$

Result given by Tikkiwal, B.D. (1960) is that the basic assumption for regression estimator is that sample size 'n' should follow bivariate normal distribution. However, regression estimator for wastage is more efficient than ratio estimator but it is better to use ratio estimator because ratio estimator has very less assumptions required as compared to regression estimator.

Further, let estimators of measure of external wastage be obtained respectively by replacing capital letter by small letters in $1 \& 2$ of section $\mathrm{C}$.

Thus,

$\mathrm{n}=\mathrm{n}_{\mathrm{e}}+\mathrm{n}_{\mathrm{ne}}+\mathrm{n}_{\mathrm{ee}}$ $\mathrm{w}_{\mathrm{ne}}=\mathrm{n}_{\mathrm{ne}} / \mathrm{n} ; \mathrm{w}_{\mathrm{ee}}=\mathrm{n}_{\mathrm{ee}} / \mathrm{n}$ and $\mathrm{w}_{\mathrm{e}}=\mathrm{w}_{\mathrm{ne}}+\mathrm{w}_{\mathrm{ee}}$

\section{Estimators for $w_{n e}, w_{\text {ee }}$ and $w_{e}$}

$\mathrm{w}_{\mathrm{ne}}=\frac{\mathrm{p}_{1}}{\overline{\mathrm{v}}} ;$ where $\mathrm{p}_{1}=\mathrm{n}_{\mathrm{ne}} / \mathrm{n}$

$\mathrm{w}_{\mathrm{ee}}=\frac{\mathrm{p}_{2}}{\overline{\mathrm{v}}} ;$ where $\mathrm{p}_{2}=\mathrm{n}_{\mathrm{ee}} / \mathrm{n}$

$\mathrm{w}_{\mathrm{e}}=\frac{\mathrm{p}_{3}}{\overline{\mathrm{v}}} ;$ where $\mathrm{p}_{3}=\mathrm{n}_{\mathrm{e}} / \mathrm{n}$

(i) Bias and Mean square error for $w_{n e}$

$$
\begin{aligned}
& \widehat{\operatorname{BiaS}}\left(\mathrm{W}_{\mathrm{ne}}\right)_{r} \simeq \frac{1}{n}\left(p_{1} S_{v}^{2}-S_{u v}^{2}\right) \\
& \widehat{\operatorname{MSE}}\left(\mathrm{W}_{\mathrm{ne}}\right)_{r} \simeq\left(\frac{1}{\mathrm{n}}+\frac{1}{\mathrm{~N}}\right) \mathrm{S}_{\mathrm{uv}}^{2}
\end{aligned}
$$


Gupta, M.K.

Prasad, J.

Gupta, P.C.

where $s_{\mathrm{uv}}^{2}=\frac{1}{\mathrm{n}-1} \sum_{\mathrm{i}=1}^{\mathrm{n}} \frac{\mathrm{M}_{\mathrm{i}}^{2}}{\overline{\mathrm{M}}^{2}}\left(\mathrm{w}_{\mathrm{ne}}^{\mathrm{i}}-\mathrm{w}_{\mathrm{ne}}\right)^{2} ; \mathrm{w}_{\mathrm{ne}}^{\mathrm{i}}$ is the proportion of the never enrolled children in the $\mathrm{i}^{\text {th }}$ cluster

(ii) Bias and Mean square error for $\mathrm{w}_{\mathrm{ee}}$

$$
\begin{gathered}
\widehat{\operatorname{Bias}}\left(\mathrm{W}_{\mathrm{ee}}\right)_{r} \simeq \frac{1}{n}\left(p_{2} S_{v}^{2}-S_{u v}^{2}\right) \\
\widehat{\operatorname{MSE}}\left(\mathrm{W}_{\mathrm{ee}}\right)_{r} \simeq\left(\frac{1}{\mathrm{n}}-\frac{1}{\mathrm{~N}}\right) \mathrm{S}_{\mathrm{uv}}^{2}
\end{gathered}
$$

where $s_{\mathrm{uv}}^{2}=\frac{1}{\mathrm{n}-1} \sum_{\mathrm{i}=1}^{\mathrm{n}} \frac{\mathrm{M}_{\mathrm{i}}^{2}}{\overline{\mathrm{M}}^{2}}\left(\mathrm{w}_{\mathrm{ee}}^{\mathrm{i}}-\mathrm{w}_{\mathrm{ee}}\right)^{2} ; \mathrm{w}_{\mathrm{ee}}^{\mathrm{i}}$ is the proportion of the dropout children in the $i^{\text {th }}$ cluster

(iii) Bias and Mean square error for $\mathrm{w}_{\mathrm{e}}$

$$
\begin{aligned}
& \widehat{\operatorname{BiaS}}\left(\mathrm{W}_{\mathrm{e}}\right)_{r} \simeq \frac{1}{n}\left(p_{3} S_{v}^{2}-S_{u v}^{2}\right) \\
& \widehat{\operatorname{MSE}}\left(\mathrm{W}_{\mathrm{e}}\right)_{r} \simeq\left(\frac{1}{\mathrm{n}}+\frac{1}{\mathrm{~N}}\right) \mathrm{S}_{\mathrm{uv}}^{2}
\end{aligned}
$$

where $s_{u v}^{2}=\frac{1}{n-1} \sum_{i=1}^{n} \frac{M_{i}^{2}}{\bar{M}^{2}}\left(w_{e}^{i}-w_{e}\right)^{2} ; w_{e}^{i}$ is the proportion of the out-of-school children in the $i^{\text {th }}$ cluster

This sampling technique for measurement of external wastage can be illustrated with live data:

Rajasthan Elementary Education Council, Jaipur conducted a household survey in the year 2010 to develop a child tracking system for all the children of the age group 6-14 years but due to so many limitations, it did not continue for further next years. But by this exercise, a comprehensive database of Rajasthan state's children of age group 6-14 yrs of the year 2010 is available (www.rajssa.nic.in).

\begin{tabular}{clcc}
\hline S. No. & District & $\begin{array}{c}\text { Population of } \\
\text { children of the age } \\
\mathbf{6 - 1 4} \text { yrs (Mi) }\end{array}$ & $\begin{array}{c}\text { No. of out of } \\
\text { school children } \\
\text { (OOSC) }\end{array}$ \\
\hline 1 & GANGANAGAR & 311664 & 25190 \\
2 & HANUMANGARH & 266120 & 31577 \\
3 & BIKANER & 401176 & 57537 \\
4 & CHURU & 341109 & 42308 \\
5 & JHUNJHUNUN & 386784 & 16082
\end{tabular}




\begin{tabular}{|c|c|c|c|}
\hline S. No. & District & $\begin{array}{l}\text { Population of } \\
\text { children of the age } \\
\text { 6-14 yrs (Mi) }\end{array}$ & $\begin{array}{l}\text { No. of out of } \\
\text { school children } \\
\text { (OOSC) }\end{array}$ \\
\hline 6 & ALWAR & 693138 & 36787 \\
\hline 7 & BHARATPUR & 486426 & 43814 \\
\hline 8 & DHAULPUR & 252105 & 16318 \\
\hline 9 & KARAULI & 281977 & 21138 \\
\hline 10 & SAWAI MADHOPUR & 244633 & 23552 \\
\hline 11 & DAUSA & 322998 & 15994 \\
\hline 12 & JAIPUR & 1027862 & 55434 \\
\hline 13 & SIKAR & 494421 & 22107 \\
\hline 14 & NAGAUR & 609682 & 57949 \\
\hline 15 & JODHPUR & 620234 & 79904 \\
\hline 16 & JAISALMER & 129845 & 26208 \\
\hline 17 & BARMER & 526721 & 92227 \\
\hline 18 & JALOR & 390890 & 70870 \\
\hline 19 & SIROHI & 191395 & 40639 \\
\hline 20 & PALI & 375638 & 43142 \\
\hline 21 & AJMER & 399147 & 41484 \\
\hline 22 & TONK & 263574 & 23394 \\
\hline 23 & BUNDI & 195193 & 18746 \\
\hline 24 & BHILWARA & 377238 & 47669 \\
\hline 25 & RAJSAMAND & 199819 & 15934 \\
\hline 26 & UDAIPUR & 448076 & 69844 \\
\hline 27 & DUNGARPUR & 263881 & 27236 \\
\hline 28 & BANSWARA & 360013 & 47893 \\
\hline 29 & CHITTAURGARH & 260261 & 19936 \\
\hline 30 & KOTA & 270325 & 17070 \\
\hline 31 & BARAN & 217667 & 16911 \\
\hline 32 & JHALAWAR & 232793 & 24564 \\
\hline \multirow[t]{2}{*}{33} & PRATAPGARH (RAJ.) & 127520 & 21459 \\
\hline & Total & 1210917 & 11970325 \\
\hline
\end{tabular}

Measurement of Yearly Wastage in Elementary

Education 
Gupta, M.K.

Prasad, J.

Gupta, P.C.
Rajasthan state consists of 33 districts. These districts can be subdivided in 32 ways. Subdivision of 33 districts in 7 clusters is most appropriate because this combination has the highest 'p' value with maximum degree of freedom of error if made using the concept given by Levene's test of homogeneity. Hence, in this combination, homogeneity between clusters is maximum than other possible combinations. The following gives the clusters obtained by as per above cited criterion using SPSS statistical software: 


\begin{tabular}{|c|c|c|c|c|}
\hline \multirow{2}{*}{6} & 1. Jaisalmer & & & \multirow{6}{*}{$\begin{array}{r}\text { Measurement of } \\
\text { Yearly Wastage } \\
\text { in Elementary } \\
\text { Education }\end{array}$} \\
\hline & 2. Sirohi & 66847 & 321240 & \\
\hline \multirow{4}{*}{7} & 1. Barmer & 184556 & 1045131 & \\
\hline & 2. Jalore & & & \\
\hline & 3. Pratapgarh & & & \\
\hline & Total & 1210917 & 11970325 & \\
\hline
\end{tabular}

Now, out of 7 clusters, we have to select a sample of 'n' clusters by using simple random sampling without replacement (SRSWOR).

Though the Levene's test suggests $n=2$, but in order to get reliable estimator for the mean square estimator of the estimator of the proportion, we have decided to take $n=3$.

For, $\mathrm{N}=7, \mathrm{n}=3$

We select $2^{\text {nd }}, 3^{\text {th }}$ and $5^{\text {th }}$ cluster in the sample by using SRSWOR,

The estimated value of external wastage will be:

$$
\mathrm{w}_{\mathrm{e}}=0.185854(0.101160) \text {, }
$$

The estimate of bias for ratio estimator:

$$
\widehat{\operatorname{Bias}}\left(\mathrm{W}_{\mathrm{e}}\right)_{r} \simeq 0.021964
$$

The estimate of mean square error for ratio estimator:

$$
\begin{aligned}
& \widehat{\operatorname{MSE}}\left(\mathrm{W}_{\mathrm{e}}\right)_{r}=0.00325543 \\
& \widehat{\mathrm{SE}}\left(\mathrm{W}_{\mathrm{e}}\right)_{r} \simeq 0.057056
\end{aligned}
$$

The estimate of bias for regression estimator:

$$
\widehat{\operatorname{Bias}}\left(\mathrm{W}_{\mathrm{e}}\right)_{\text {reg }} \simeq 0
$$

The estimate of mean square error for regression estimator:

$$
\begin{aligned}
& \widehat{\operatorname{MSE}}\left(\mathrm{W}_{\mathrm{e}}\right)_{\text {reg }} \simeq 0.00041822 \\
& \widehat{\mathrm{SE}}\left(\mathrm{W}_{\mathrm{e}}\right)_{\text {reg }} \simeq 0.064670
\end{aligned}
$$

The estimated value of wastage due to never enrollment and wastage due to dropout can also be measured by this technique. The actual values of the parameters are given in parenthesis. It can be seen that true value lies within $2 \sigma$ limits. 
Gupta, M.K.

Prasad, J.

Gupta, P.C.

\section{CONCLUDING REMARKS}

There are two parameters of universal elementary education that are universal enrollment and universal retention. So, in order to measure the performance of elementary education system, we should measure these two parameters. the performance of elementary education depends upon the magnitude of the educational wastage. Educational wastage cab be classified in two parts i.e. Internal wastage and External wastage. Internal wastage represents economic wastage by the in-school children due to dropout, repetition and non-promotion. After the effective implementation of Right to Education Act-2010, cases of repetition and non-promotion reduced to a great extent and negligible because this improved the quality of elementary education. So, dropout is the major factor of internal wastage. Dropout is the two-way wastage i.e. wastage of economic resources as well as human resources. The question arises that whether or not the actual dropout can be measured by cohort method? In our school system, it is a common practice that fake enrollments are being made in order to improve the pupil teacher ratio, as decrease in it may result in abolishment of posts of the school teachers. Further, it is seen that the children left out the school without telling or informing the actual reason to the school authorities.

In fact, the external wastage is the most serious wastage which is an integral part of the human resource wastage. It measures the two major factors of universal elementary education viz wastage due to non-enrollment (never enrolled) and non-retention (dropout). These both categories constitute the out of school children, so to find out these two factors, we can focus on out of school children only.

It can also be concluded that a web based real time child tracking system (CTS) for all children population of the age group 6-14 years is necessarily required to get the actual position of elementary education system in India and measurement of external wastage. But CTS for out-of-school children is not being done in India. In this situation, to measure the external wastage, a sample survey may be conducted yearly by suggested method and the wastage can be estimated.

\section{REFERENCES}

A statistical study of wastage at school (1972). A study prepared for International bureau of Education by the UNESCO office of Statistics.

Adhvaru, J.H. (1969). The theory of investment in Human Capital. The measurement of cost productivity and efficiency of Education (ed. By H.N. pandit), 136-45, NCERT, New Delhi.

Alejandro M. Fernández Castro (2008). A means of assessing the wastage of efficiency in undergraduate education CESUGA - University College Dublin, National University of Irelan.

Mathematical Journal of Interdisciplinary Sciences, Volume 2, Number 1, September 2013 
Hajela, D. \& Tikkiwal, B.D. (1969). Wastage in Education and Measures to Prevent it. Measurement of cost productivity and efficiency of education, NCERT, Pub., PP-146-63.

Kamat, A.R. (1968). Estimating wastage in a course of Education, Sankhya, Series-B:30, 5-12.

Mehta, Arun C. (2004). Indicators of educational development with focus on elementary education: concept and definitions, National Institute of Educational planning and administration (NIEPA), New Delhi.

Mehta, Arun C (2008). Dropout rate at primary level: A note based on DISE 2003-04 \& 2004-05 data, NIEPA, New Delhi.

P.V. Sukhatme, B.V. Sukhatme, S. Sukhatme \& C. Asok (1984). Sampling Theory of Surveys With Applications - Indian Society of Agricultural Statistics, New Delhi

Rajasthan SSA Portal www.rajssa.nic.in

Rao, G.N. \& Tikkiwal, B.D. (1966). An intrigated approach to the study of wastage in a given course of education. Sankhya Vol.28, series-B, 229-36 .

Singh, D. (1980). Sample Survey Methods in Education. Demographic and Educational Statistics of india, 139-45.

Tikkiwal, G.C. (1977). Some statistical aspects of measurement of wastage in education (Abstract), Proceedings of $64^{\text {th }}$ annual series of the Indian Science Congress Association part III, p.40.

Tikkiwal, G.C. (1978). On Sampling Approach to the Measurement Problem of the Wastage in Education. Ph.D. thesis, university of Rajasthan, Jaipur.

Tikkiwal, G.C. \& Tikkiwal, B.D. (1983). An alternative approach to the sampling theory of measurement problem of wastage in education. Bulletin of international Statistical institute, 2, 850-53.

Tikkiwal, B.D. \& Tikkiwal, G.C. (1993), Measurement of Wastage in Education : A Review, Jour. Educational Planning and Administration, VII, 3, 293-308.

Tikkiwal, B.D. \& Tikkiwal, G.C. (2000). Measurement of Wastage and therefore of Efficiency of Education. Statistics, Development and Human Rights: IAOS Conference 2000. Montreux, Switzerland.

Tikkiwal, B.D. (1960). On the theory of classical regression and double sampling estimation, J. Roy. Stat.Soc., Series B, 22, 131-138.
Measurement of Yearly Wastage in Elementary

Education 